\title{
Positive and/or Negative Meaning as Style Traits and Strategy Throughout the 2016 American Presidential Campaign - Hillary Clinton and Donald Trump
}

\author{
Lecturer Aurelia Ana VASILE, PhD \\ Faculty of Journalism and Communication Studies, University of Bucharest \\ E-mail: aurelia-ana.vasile@fjsc.ro
}

\begin{abstract}
Communication has to do with influence that has impact on the life of those involved in the communication process, mostly when this communication refers to political campaigning. Inspired by the research on stress performed by the endocrinologist Hans Selye (1974), we aimed at investigating the polarity of meaning in the language of electoral campaign, in order to check if this kind of communication gets more polarized in terms of meaning as the campaign is approaching its end towards the polls. The discourse analysis corpus was that of six comparable Hillary Clinton and Donald Trump transcript excerpts from speeches at various stages earlier and later throughout the campaign for the 2016 presidential elections in the U.S.A. The results of our analysis have shown that Donald Trump's campaign discourses were generally significantly more polarized than those of Hilary Clinton's. The most generally polarized discourse was, by far, that of Trump on immigration, and the least generally polarized was Trump's at an event (Al Smith Dinner). The most positively polarized was Hilary Clinton's on immigration, and the least positively charged was Trump's referring to the great leader. The most negatively polarized discourse was Trump's one on immigration, as it reached more than $10 \%$ of negative words, whereas the least negatively polarized was Hilary Clinton's on national service.
\end{abstract}

Keywords: communication, positive/negative connotation, politics, campaign, discourse. 


\section{Introduction: Context}

In a broader sense, communication is inherently about influence and exchange of influence that has impact on the life of those involved in the communication process, and this fact strongly applies to political communication. Political campaigns mostly stand for such processes refering to communication and, consequently, to broader areas of life. Within such a context, a speech may be "a window" towards a great historical event (Montefiore, 2014, 10), as well.

Why would we focus on the 2016 campaign for the president of the U.S.A.?

Obviously because of the special interest aroused worldwide (in the media) by the widely acknowledged fact that the politician who becomes the president of the U.S.A. has much power over and impact on the world's most prominent future policy decisions.

Subsequently, first, the U.S.A., as a state, plays a key part worldwide nowadays, within NATO, as well.

Then, for Romanian researchers, as Romania is a NATO member state, this topic is of pragmatic utmost importance, mostly as the country is geopolitically challenged by its setting at the Eastern borders of the European Union.

And thirdly, there was a claimed involvement of other state intelligence services in the 2016 campaign for the president of the U.S.A., which makes the whole campaigning process become more intriguing for research.

Polarized language has not been dwelt on in the field of communication research so far, mostly focusing on political campaigning, which nowadays, as much as ever, shows tense approaches to communication for the sake of electoral success.

This study may offer a new angle or approach (both theoretically and in terms of practice) to communication strategies in political campaigning and to their outcomes, which we deem may contribute significantly to the mainstream research data in the field.

\section{Theoretical Framework:}

\section{Stress of Political Campaigning and Polarized Meaning}

Meaning - attributed to words, expressions, sentences, or to other types of communication items (non-verbal, as well) - plays a crucial part in communication. According to Alex Mucchielli $(2006,183)$, various types of behavior are triggered by the meaning assigned to them by the social actors involved, and this behavior represents something that makes sense to those that adopt it and to those that witness it.

Consequently, voting behavior is believed to be influenced by the characteristics of political discourse, mostly throughout electoral campaigning, which makes 
this endeavor even tenser and costlier (both financially and psychologically) for politicians and for their staffs.

The sociologist Anthony Giddens $(2000,376)$ noted that the percentage of voters who declared that they made up their mind upon a choice at the polls throughout the campaign was increasing. Therefore, we may consequently infer that investigations on political campaign communication are relevant from the outset, since voters may make up their mind upon their call owing to the impact of the campaign.

Usually it is quite obvious and common knowledge that politicians tend to use stronger language, in order to be more convincing, as elections draw nearer.

Endocrinologist Hans Selye's research presented in the volume Stress without Distress (1974) dwelt on the underlying inherent organic mechanisms that engender polarized endocrinological processes that have to do with comfort or discomfort in communication (and hence with possible eliciting rejection or reception of message).

Positive stress was called eustress by Hans Selye (in Petticrew, M.P. \& Lee, K. 2011, 411-418), and his research showed that such stress had a healing effect on the body, as the hormones of happiness were generated. On the other hand, the negative stress, coined by Selye as distress, brought about toxic undesirable hormonal processes in the body, as the undergone research showed. He emphasized the polarity of such endocrinological processes.

His research inspired us into investigating the polarity of meaning in the language of electoral campaign, in order to check if this language meaning gets more polarized as the campaign is approaching its end towards the polls.

Then, a subsequent comparison of our study results to the actual outcomes at the polls, may eventually also provide relevant information about the correlation between the ratio/statistics of polarized discourse, and of positive versus negative meaning for each of the main two opposing candidates, and their ranking after the polls.

\section{Research Design, Methodology}

The aim and the objectives of our research endeavor refer to analyzing the polarity of meaning in the language used by the two top runners for presidency in the nowadays worldwide impacting U.S.A., Hilary Clinton and Donald Trump. This analysis is meant to show correlations between this polarized communication and the stage in the electoral campaign, and of the outcomes at the polls.

Thus, the main hypothesis that we have focused on was that the closer to ellection time/polls, the more polarized (either in terms of positive or of negative meaning attached to verbal communication) the political discourse of opposing candidates throughout the campaign. 
A secondary hypothesis may be the one that states the fact that, the more polarized the verbal communication throughout the campaign speeches, the more successful the candidate (the better ranked in the outcomes at the polls).

Our methodological approach was that of comparative content, discourse analysis. The language/discourse items analyzed were both those lexically and semantically autonomous or context-related either positive or negative (polarized), and their ratio from the total number of meaning units/items in the discourse transcript.

The type of positively polarized language items selected may be like the following: thank, heroes, love, owe, great, etc., and they belong to various morpho-syntactic categories, as well as those negatively polarized like: hostility, fear, nothing funny, division, etc.

The discourse analysis corpus was that of six comparable (in terms of similar/comparable topics approached) Hillary Clinton and Donald Trump transcript speeches at various stages earlier and later throughout the campaign for the 2016 presidential elections in the U.S.A. The selection was made as transcripts were available on line, and referred to speeches at various times throughout the period preceding the elections. The speeches by the two politicians were: for both focused on an event (October 20th, 2016, the Al Smith Dinner), and on immigration (2nd of September 2016 - Donald Trump, and 15th September-Hilary Clinton, at the Congressional Hispanic Caucus Institute), and then, for each: on national service (on 30th September 2016, for Hilary Clinton) versus the great leader (by Donald Trump, on the 22nd of August 2016).

The source for Hilary Clinton's speeches was her blog, https://www.hillaryclinton.com/blog/speeches/, and for Donald Trump's was https://www.google. ro/?gws_rd=cr\&ei=_37uV-XOFMj8swGwt4vYDA\#q=donald+trump+speech+trans cripts. Donald Trump's campaign blog/website could not be used as a source for speech transcripts, as it did not contain any of these. The home page of it asked for sponsorship for the campaign, without tracking any information regarding Trump's speeches.

\section{Results and Interpretation/Discussion}

The results obtained, have shown some interesting facts. Weighing the polarity of the language units (words or expressions/phrases) was the most challenging part, and also the most rewarding, in analyzing the language used by the two candidates running for presidency. In other words, it was not easy to decide what were the words either positively or negatively charged, and to leave out the neutral ones.

The following data emerged from our analysis, as it shows in the tables and charts below. 
Table 1. Ratio of polarized language in Hilary Clinton discourse excerpts

(15th September-20th October 2016)

\begin{tabular}{|c|c|c|c|}
\hline $\begin{array}{c}\text { Hilary Clinton Discourse } \\
\text { time and topic }\end{array}$ & $\begin{array}{c}\text { Total ratio } \\
\text { of polarized language }\end{array}$ & $\begin{array}{c}\text { Positively } \\
\text { polarized language }\end{array}$ & $\begin{array}{c}\text { Negatively } \\
\text { polarized language }\end{array}$ \\
\hline $\begin{array}{c}\text { 15 September 2016 } \\
\text { (on immigration) }\end{array}$ & $13.93 \%$ & $11.28 \%$ & $2.65 \%$ \\
\hline $\begin{array}{c}30 \text { September 2016 } \\
\text { (on national service) }\end{array}$ & $11.79 \%$ & $11.12 \%$ & $0.67 \%$ \\
\hline $\begin{array}{c}\text { 20 October 2016 } \\
\text { (at event) }\end{array}$ & $11.38 \%$ & $8.02 \%$ & $3.36 \%$ \\
\hline Average ratio & $12.36 \%$ & $10.14 \%$ & $2.23 \%$ \\
\hline
\end{tabular}

Table 2. Ratio of polarized language in Donald Trump discourse excerpts (22nd August-20th October 2016)

\begin{tabular}{|c|c|c|c|}
\hline $\begin{array}{c}\text { Donald Trump Discourse } \\
\text { time and topic }\end{array}$ & $\begin{array}{c}\text { Total ratio } \\
\text { of polarized language }\end{array}$ & $\begin{array}{c}\text { Positively } \\
\text { polarized language }\end{array}$ & $\begin{array}{c}\text { Negatively } \\
\text { polarized language }\end{array}$ \\
\hline $\begin{array}{c}\text { 22 August 2016 } \\
\text { (on great leader) }\end{array}$ & $13.66 \%$ & $3.73 \%$ & $9.93 \%$ \\
\hline $\begin{array}{c}\text { 2 September 2016 } \\
\text { (on immigration) }\end{array}$ & $17.02 \%$ & $6.22 \%$ & $10.79 \%$ \\
\hline $\begin{array}{c}\text { 20 October 2016 } \\
\text { (at event) }\end{array}$ & $10.01 \%$ & $6.77 \%$ & $3.24 \%$ \\
\hline Average ratio & $13.56 \%$ & $5.57 \%$ & $7.99 \%$ \\
\hline
\end{tabular}

Table 3. Comparative polarization of language for the candidates for presidency, according to the speech topic approached: Al Smith Dinner, speech at event

\begin{tabular}{|c|c|c|c|c|c|c|c|}
\hline Candidate & 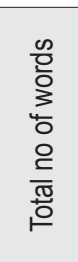 & 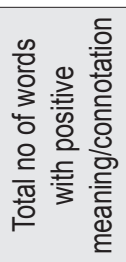 & 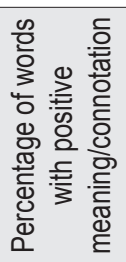 & 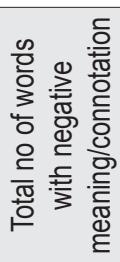 & 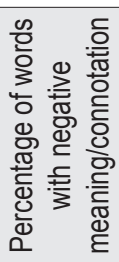 & 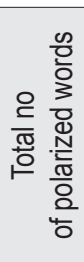 & 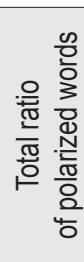 \\
\hline Hillary Clinton & 2320 & 186 & 8.02 & 78 & 3.36 & 264 & 11.38 \\
\hline Donald Trump & 1699 & 115 & 6.77 & 55 & 3.24 & 170 & 10.01 \\
\hline
\end{tabular}

Table 4. Comparative polarization of language for the candidates for presidency, according to the speech topic approached: Immigration

\begin{tabular}{|c|c|c|c|c|c|c|c|}
\hline Candidate & 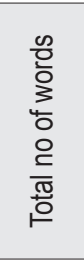 & 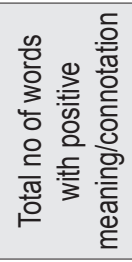 & 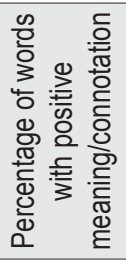 & 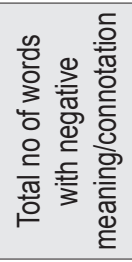 & 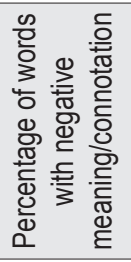 & 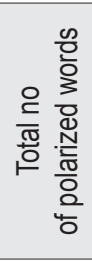 & 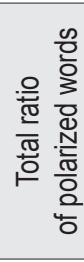 \\
\hline Hillary Clinton & 2642 & 298 & 11.28 & 70 & 2.65 & 368 & 13.93 \\
\hline Donald Trump & 1575 & 98 & 6.22 & 170 & 10.79 & 268 & 17.02 \\
\hline
\end{tabular}


Table 5. Comparative polarization of language for the candidates for presidency, according to the speech topic approached: national service/great leader

\begin{tabular}{|c|c|c|c|c|c|c|c|}
\hline Candidate & 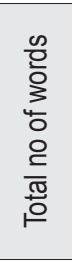 & 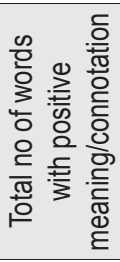 & 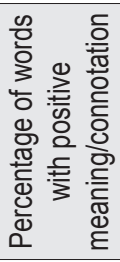 & 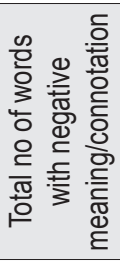 & 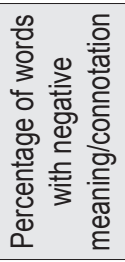 & 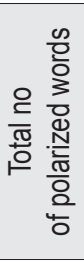 & 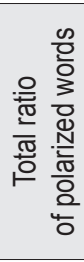 \\
\hline Hillary Clinton & 3426 & 381 & 11.12 & 23 & 0.67 & 404 & 11.79 \\
\hline Donald Trump & 1208 & 45 & 3.73 & 120 & 9.93 & 165 & 13.66 \\
\hline
\end{tabular}

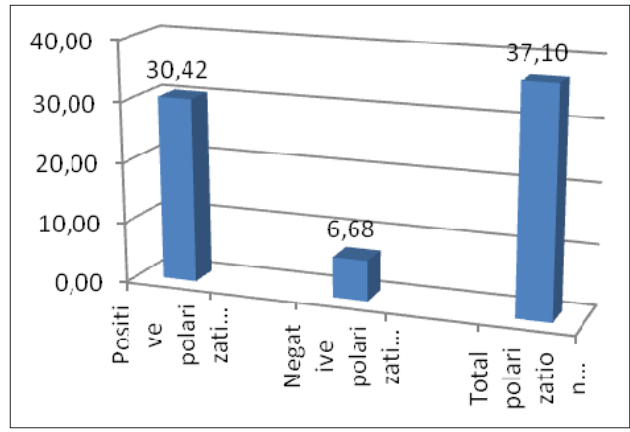

Figure 1. Added up percentages of polarized language in speeches, Hilary Clinton

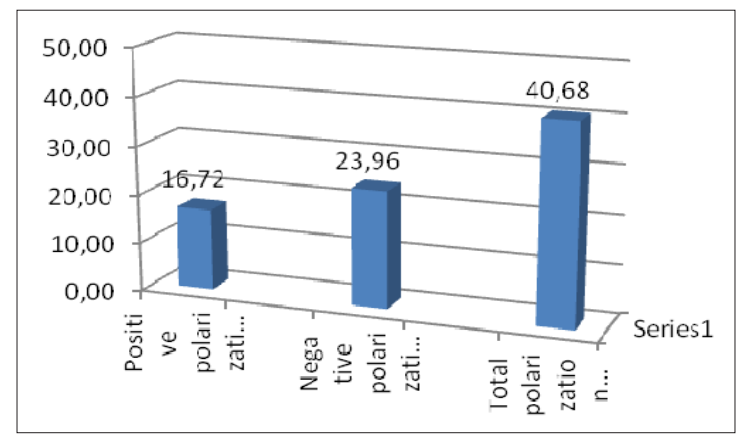

Figure 2. Added up percentages of polarized language in speeches, Donald Trump

Overall, as figures 1 and 2 show, Donald Trumps language in the speech excerpts analyzed was more polarized than Hilary Clinton's, and we know that Donald Trump won the elections. His language was by far more negatively polarized than Hilary Clinton's, whilst Hilary Clinton's language was by far more positively charged.

The fact that the runner up with the most polarized language (Donald Trump) won the elections is not surprising. However, as the law of effect (Ed- 
ward Thorndike, 1905) in behavioral psychology (connectionism) states that people tend to reject discomfort (in communication, as well), and to embrace whatever has brought comfort to them (Neil, 2007, 516), negatively charged language should have brought about a consequent outcome at the polls, and it happened differently. A possible explanation may lie in the wider context of ellections, and of political communication, that does not limit to the verbal positively or negatively charged connotations and which is tremendously a much more complex process than any kind of study may aim at encompassing.

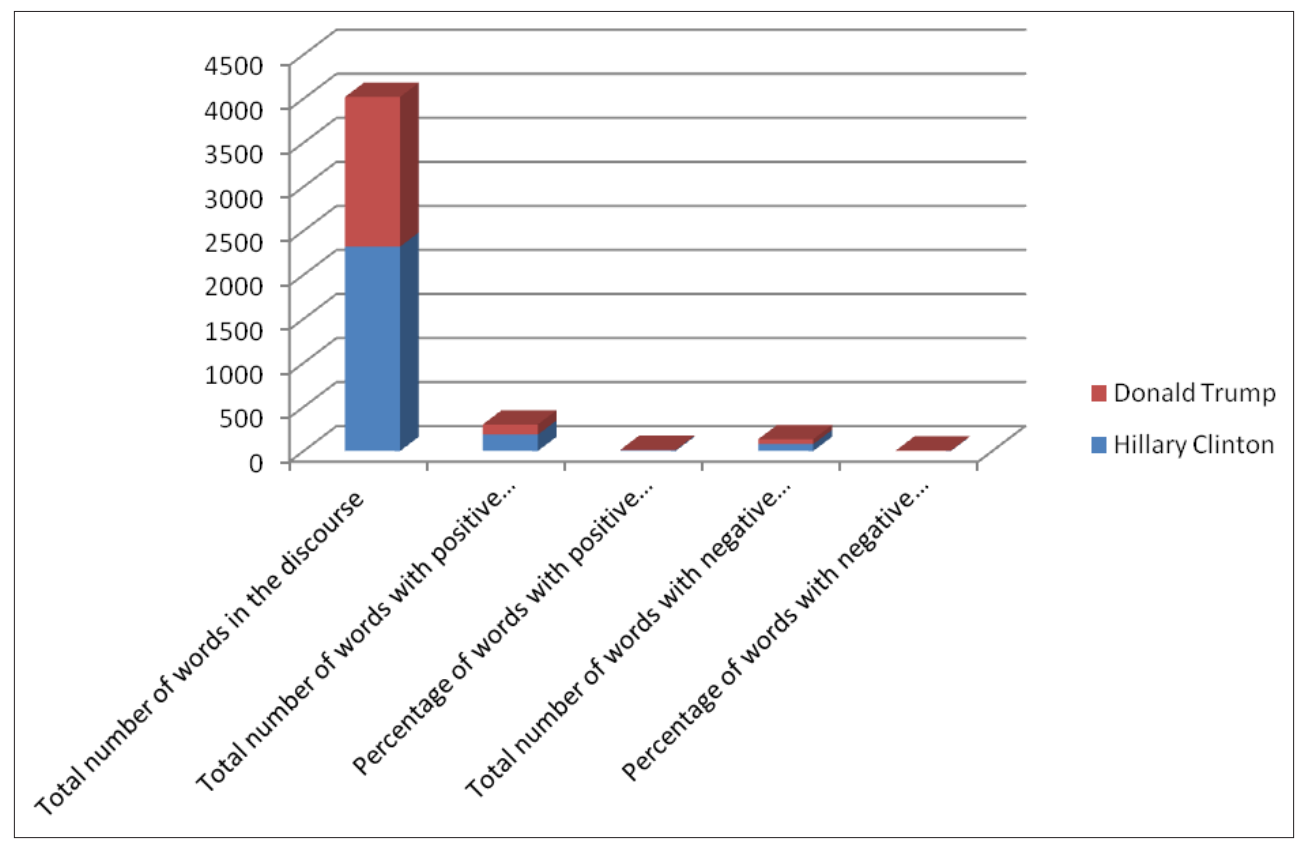

Figure 3. Number and percentage of polarized words in speeches, comparatively, Hilary Clinton and Donald Trump

Donald Trump's discourse characteristics as they appeared obvious throughout our analysis showed:

-Weaker positive connotation of language used, as compared to Hillary Clinton. (some and something, as in "something nice", not "really/absolutely nice", for instance).

- Stronger negative connotation of language used, as compared to Hillary Clinton.

- Even stronger emphasis on negative meaning words in his speech on immigration.

- With Trump most of the discourse meanings are self-centered.

- Trump's discourse vocabulary range is narrower than Hillary Clinton's 
Surprisingly, Hillary Clinton's discourse appears more polarized than expected, and quite close to Donald Trump's discourse in terms of polarization, but less polarized though, and still obviously this polarity of her language strongly leaned towards the positively charged words that were used more frequently by Hilary Clinton.

- Hilary Clinton's discourse appeared more elaborate and more careful on the use of words with polarized connotations, either positive or negative.

\section{Conclusion}

The main hypothesis was not entirely confirmed as not necessarily the drawing closer to the ellection time exhibited the more polarized verbal communication, but rather the topic approached prevailed in intensifying polarity in the discourse language used. For instance, Donald Trump showed his utmost polarized language throughout the discourse on immigration, and it was mostly negatively charged polarity, as this was a key topic to his campaign. Hilary Clinton also exhibited more intensely polarized language in the speech on immigration (the most polarized speech of hers from aming the ones we analyzed here), but it was mostly positively charged language. For both runner ups the most intensely disputed topic was that on immigration and it elicited the most charged language by both candidates, either positively or negatively.

The second, secondary hypothesis was confirmed, as the more polarized the verbal communication throughout the campaign speeches, the more successful the candidate (the better ranked in the outcomes at the polls), and Donald Trump, whose language showed more intense polarization, eventually won the elections.

As a general conclusion, semantics, i.e., meaning, plays a crucial part in communication in general, and, more specifically, in political communication throughout political campaigns, as well. However, communication contexts are by far more complex that polarized language in verbal communication, and therefore correlations referring to one aspect of communication are overwhelmed by other intricate context issues (and some may refer to back stage facts that cannot even be known by the researcher), which makes research in communication a complex and challenging endeavor.

\section{References}

1. Clinton, Hillary. Speeches. Retrieved from https://www.hillaryclinton.com/blog/ speeches/, accessed on October 1st and 24th 2016.

2. Giddens, Anthony (2000). Sociologie. București: Editura Bic All.

3. Montefiore, Simon Sebag (2015). Discursuri care au schimbat lumea. București: Editura Trei.

4. Mucchielli, Alex; Corbalan, Jean-Antoine; Ferrandez, Valérie (2006). Teoria proceselor de comunicare. Iași: Institutul European. 
5. Neil, Carlson; et. al. (2007).Psychology The Science of Behavior. New Jersey, USA: Pearson Education Canada Inc.

6. Petticrew, M.P \& Lee, K. (2011). The "Father of Stress" Meets "Big Tobacco". Hans Selye and the Tobacco Industry. American Journal of Public Health, 101 (3), pp. 411-418.

7. Trump, Donald. Speeches. https://www.google.ro/?gws_rd=cr\&ei=_37uV-XOFMj8 swGwt4vYDA\#q=donald+trump+speech+transcripts, accessed on October 1st and 24th 2016.

\section{Appendix Speech Excerpts}

- Donald TRUMP: “Our country is in serious trouble. We don't have victories anymore. We used to have victories, but we don't have them. When was the last time anybody saw us beating, let's say, China in a trade deal? They kill us. I beat China all the time. All the time.

- When did we beat Japan at anything? They send their cars over by the millions, and what do we do? When was the last time you saw a Chevrolet in Tokyo? It doesn't exist, folks. They beat us all the time." (excerpt from the discourse on Great Leader, 22nd August 2016)

- Hilary CLINTON: "tens and tens of millions of Americans do some kind of volunteering in your hometowns every single year. It's one of the best things about the American people. We are doers. We don't just shrug our shoulders when we see something that needs fixing, we don't get resigned or pathetic, or blame other people and turn on each other to find scapegoats. We roll up our sleeves, we get to work to try to make things better in our neighborhood, our community, our city, our state, our country." (excerpt from the discourse on National Service, $30^{\text {th }}$ September 2016) 